\title{
A Review of Quantitative Analysis (QA) in Production Planning Decisions Using the Linear Programming Model
}

\author{
Karibo Benaiah Bagshaw \\ Department of Management, Rivers State University, Port Harcourt, Nigeria \\ Email: bagshawkb@yahoo.com, bagshaw.karibo@rsu.edu.ng
}

How to cite this paper: Bagshaw, K.B. (2019) A Review of Quantitative Analysis (QA) in Production Planning Decisions Using the Linear Programming Model. American Journal of Operations Research, 9, 255-269.

https://doi.org/10.4236/ajor.2019.96017

Received: September 30, 2019

Accepted: November 18, 2019

Published: November 21, 2019

Copyright $\odot 2019$ by author(s) and Scientific Research Publishing Inc. This work is licensed under the Creative Commons Attribution International License (CC BY 4.0).

http://creativecommons.org/licenses/by/4.0/ cC) (†) Open Access

\begin{abstract}
The purpose of this paper was to examine the role of quantitative analysis in production planning decisions. This draws from the observed imperatives of quantitative analysis in business decisions and its capacity for predictability and enhanced decision making given the increasingly complex nature of the business environment. The paper therefore addressed the historical evolution of quantitative technique as an efficient and effective decision-making tool. The content of the paper addressed commonly applied quantitative technique in manufacturing firms today which is, linear programming and its subsequent impact on production planning decisions. The results based on a congruence of views revealed that the "best-fit" application of quantitative analysis models and tools can untangle the complexities of production and planning decision making process in order to achieve the organizational goal. This is, as literature also showed that there is obviously no consensus or integrated model that is capable of solving all managerial problem, different models such as the linear programming model have however been developed to cater for different problems as they arise. The workability or suitability of quantitative analysis is actually premised on its appropriate application. The paper recommends the application of quantitative analysis using linear programming in solving various resource allocation related issues in the primary production planning function of manufacturing firms.
\end{abstract}

\section{Keywords}

Decision Making, Linear Programming, Production Planning, Quantitative Analysis

\section{Introduction}

The production activities of manufacturing firms have significant impact on the 
Nigeria economy as they account for $10 \%$ of the total annual GDP of the country [1]. The manufacturing firms are however faced with the problem of deciding how to determine the most efficient combination of inputs required to produce the right quantity and quality at the least cost for customers' satisfaction. This brings about the issue of production planning in resource allocation with regard to how scarce resources can be effectively managed. This problem is as a result of complexities brought about by advancement in technology and rising business environmental challenges. These influences have caused significant changes to market needs which combined with the issue of limited resources, drive every organization to seek for profitable and optimal ways to utilize limited resources to meet the changing needs of the market [2]. Whether it is a production system or a service organization, it is pertinent that resources have to be optimally utilized.

Again, as the future of the manufacturing businesses evolves, it brings with it bundle of uncertainties; and ensuring an efficient production planning process becomes a critical activity that should not be done on a rule of the thumb basis by managers. It requires a robust decision making modeling geared towards optimization of input for profitable output. The decision on optimal and profitable alternatives in the management of resources is crucial, because they have far-reaching effects on the profitability, competitiveness and the ultimate survival of the organization. It is however, noted that in most manufacturing firms, rational reasoning and value of the production manager or any other manager is usually responsible for the amount of efforts and commitment the firm puts into the production process. As the roles of the managers have become complex, it is therefore required for them to make the right decisions on the efficient utilization and maximization of limited resources. This will curb the error of making wrong and costly decisions like; entering the wrong markets; producing the wrong products with poor quality; or providing inappropriate services that will severely impact on firms' outcomes. The solutions to the problems of making the right decision can be addressed by the use of quantitative analysis [3] [4].

According to the assertion of Anene and Oyelere [3], attention is now drawn to how best managers can make efficient decision in production planning in manufacturing firms in Nigeria through the application of quantitative analysis. Quantitative analysis according to them, has contributed towards the achievement of efficiency in decision making in production planning. It has taken the lead in the scientific approach to managerial decision-making. The importance of quantitative techniques (QT) otherwise known as quantitative analysis (QA) in efficient decision making cannot be over emphasized [3]. Over the years, researchers have proposed guidelines, processes, techniques and tools that can guide managers and decision makers in making favorable decisions for favorable production outcomes. These processes, guidelines, tools and techniques all started as scientific tools but have evolved over the years as a field of study known as quantitative analysis. 
The successful use of quantitative analysis by managers will aid the organizations to efficiently and accurately solve complex problems on time [5]. Although it has been established that the use of quantitative analysis in decision making leads to better decision outcomes, the application of appropriate quantitative techniques has remained a challenge to most managers. This is because managers will rather use qualitative techniques; which are based on personal judgment, opinions and past experiences for decision making; they see the use of quantitative analysis as mere waste of time. To solve the problem of indecisiveness of production managers in the appropriateness and applicability of quantitative analysis in production planning decisions, this paper therefore, seeks to examine the place of quantitative analysis in production planning decisions. Through a systematic narrative and review of the evolution of quantitative analysis, the paper focuses on examining the applicability of the commonly used quantitative techniques-linear programming in production planning and its impact on production efficiency. The paper contributes to the quest for a solution to the problem of determining the appropriateness and applicability of the linear programming technique in production planning to ensure efficiency production outcomes.

\section{Literature Review}

\subsection{Decision Making}

Decision-making is a pervasive phenomenon that is arguably the most critical task that a manager must undertake to avert making bad choices which can have detrimental effect on the decision maker as well as on the firm. To give a better understanding of the concept of decision making, the paper reviewed series of literature on the concept of decision making. Robbins and De Cenzo [6] defined decision making as the selection of a preferred course of action from two or more alternatives. Merton and Samuelson [7] posits that decision making is a choice that represents a course of action regarding what must or must not be done. The emphasis is on the position at which premeditated policies and objectives are transformed to actualization.

Furthermore, decision making is a process of generating, evaluating, and selecting an option or course of action from a set of at least two alternatives [8] [9]. It is the selection of the most appropriate and beneficial decision alternative in optimizing the objectives of the firm for its survival, growth and competitiveness in the given turbulent uncertain business environment. Other scholars express decision making as a process designed to isolate an appropriate alternative action from other options [10] [11]. These explanations on decision making shows that decision making is concerned with the future and involves the act of selecting one course of action from alternative courses of actions. From a different perspective, Filippo \& Mussinger [12] defined decision making as the process a manager uses to determine the process of transformation activities of a social system. On another hand, Harris [13] came up with two broad definitions of de- 
cision making: 1) It is the process of identifying and selecting amongst an array of alternatives with regards to the preferential values placed on the alternatives by the decision maker; and 2) It is the process in which uncertainty and doubts regarding alternatives in solving an identified decision problem are adequately reduced to the level such that making a reasonable choice from among them is easier.

Organizational decision making processes are the choices from among two or more alternatives. The decision making process involves arriving at the optimum decision among various alternatives. The decision-making process had been stated to involve two main frames or stages: the problem identification stage and the problem-solving stage [14]. The problem identification stage involves having information about the environment and the organization itself in assessing her performance and to note areas of failure. The decision solving stage is the actual process of decision-making. It involves the choice of an action from alternative actions or strategies and its implementation. Daft [14] had classified organizational decisions as programmed and non-programmed.

Programmed decisions are repetitive and have established procedure for solving and resolving identified problems. They are said to be structured with adequate information on performance and alternative solutions specified and the decision situations are relatively certain. However, non programmed decisions do not have a clear environment and the decision situation can be termed to be risky or uncertain. Many non programmed decisions involve strategic planning, because of the high degree of competition in the decision environment and the uncertainty of the decision outcome [14]. The business environment is in a state of flux with increased complexity and unpredictability and yet business managers are required to swim through the turbulent environment.

\subsubsection{Decision Making Steps}

The steps in making a good decision are basically the same no matter the type of decision needed in solving an identified problem.

The Steps are:

1) Monitor the Decision Environment: This requires that the manager should notice and monitor internal and external information that shows deviations from earlier planned or acceptable behavior.

2) Define the Decision Problem: The manager should know the essential details of the problem as to know the deviation that occurred.

3) Specify Decision Objectives: By determining the expected performance outcomes.

4) Diagnose the Problem: This involves analyzing the situation, identifying the deviations to set out objectives. The problem diagnosis should be stated, for example, whether to expand product line or develop a new product as product growth strategy.

5) Develop Alternative Solutions: This can be done by brainstorming or by personal experience in developing alternative solutions. 
6) Evaluation of Alternative Solutions: The alternative solutions which are courses of actions or strategies need to be evaluated as to identify the optimal solution.

Each of these steps requires adequate information and knowledge of the decision environment. The conditions in the decision environment can be controlled or non-controlled and in most business decisions the decision environment is uncontrolled. The dynamics of the decision process is associated with uncertainty and turbulence in the business environment especially in Nigeria. The choice among alternatives is the essence of decision making where the outcomes from the different alternative solutions are listed, evaluated and the choice of the alternative solutions made, after accurate assessment of the result of each of the alternative solutions. This accurate assessment involves analysis of the monetary value or benefit and the cost involved in making each alternative solution as to assess the overriding cost-benefit analysis that results in the best alternative solution. The decisions made from the alternative are implemented and monitored as to have a feedback mechanism in control of the system [15]. In addition, to some basic fundamentals in decisions making, are that;

1) The alternative that is chosen must have the higher or highest prospect of being successful or effective and be suitable for the intended goals and objectives.

2) In the theory of making choices, there is no room for making no choice, that there must be genuine alternatives to choose from. This means that in making choices, only "Do this" or "Do something else" exists.

3) Every decision must be made with a degree of rational judgment which usually manifests in the form of measures that reveals the values and preferences of the decision maker. These values and preferences are dependent on the decision maker's environment. This implies that the choices made in an uncertainty situation is dependent on a series of objective and subjective contingent factors such as information, technological knowledge, individual make-up of the decision maker, attitudes against risk.

4) Decisions are not made with absolute certainty because the possibility of having complete knowledge of all the alternatives is rare.

5) Finally, every decision involves a certain amount of uncertainty. This implies that when there is no uncertainty, what one does is called algorithm (a set of steps to be adhered to that leads to a fixed or known result).

\subsubsection{The Features of Decision-Making}

The decision making task has six features which are; 1) It is a process, 2) It involves rational thinking which makes use of the reasoning capability of the human brain, 3) It involves selection from different choices, 4) It is done with a purpose relating to the end result, 5) It is usually positive; aiming for the desired outcome, and 6) It requires commitment from the decision maker as the outcome depicts success rating of the decision maker. According to Bagshaw and Nissi (6), the process of decision making is made up of the first five steps of a 
problem-solving process which are:

1) Identifying and defining the problem,

2) Determining the set of alternative solutions,

3) Determining the criterion or criteria that will be used to evaluate the alternatives,

4) Evaluating the alternatives, and

5) Choosing an alternative.

\subsection{Quantitative Analysis}

The uncertainties and complexity experienced in manufacturing operations has made the efficient and optimal utilization of both tangible resources (land, labour, finance, equipment, machines) or intangible resources (information, processes, copyright, trade mark) dominant to every organization, and this has consequently made the managerial task of decision making a necessity.

Efficient managerial decision-making has thus become a crucial activity that should not be made on a rule-of-the-thumb basis. The use of instinct alone in decision making has not been able to address the task of choosing the most optimal and profitable courses of action among several alternatives. In order to improve the process and outcome of decision making and thus get a favorable production outcome, there is the need for production managers in manufacturing firms to apply scientific techniques, now known as quantitative techniques in their decision-making task. Quantitative techniques have different terminologies with different authors. For Anene and Oyelere [3], quantitative technique (QT) can be referred to as quantitative analysis (QA), operations research (OR), analytical technique (AT), decision science (DS), among others. For this paper, it would be referred to as quantity analysis (QA) and often times used interchangeably with quantitative techniques.

\subsection{The Basics of Production Planning}

Manufacturing firms adopt diverse production types. Nonetheless, the main objective of any type of production system adopted by a firm is to; maximize profit, minimize costs, increase work efficiency and productivity, and increase customers' satisfaction, among others. However for any of these objectives to be achieved, the production manager must have a good production planning system in place; which must include control, allocations, inspections, quality control, maintenance and repairs, research and development, employee health and safety, inventory, trainings etc. This means that every aspect of the production planning system must align with the main objective of the system. According to MacCarthy [16], production planning is considered as a function that brings about the realization of all production objectives as stated earlier. The production planning guides the production process on "how", "where" and "when" work is to be done [3]; it also guides "what" work is to be done.

From this assertion, Anene and Oyelere [3] posits that the production plan- 
ning function involves the coordination, control and regulation of the use of manpower, machines and other production resources for efficient and cost-effective production outcome that meets customers' demand. Anene and Oyelere [3] further broke down the production planning function into the following tasks:

Inventory Control: This involves the regulation of stock quantities and issuing of production materials as well as tools.

Routing and Scheduling. This involves the planning of processing methods and the sequence of operations by deciding which machine to use, how long to use it, when to use it and who uses it.

It also involves establishing the rate of output, duration of production showing the beginning and ending dates of production.

Dispatching: This involves carrying out manufacturing orders through clerical control of work on the factory floor which speeds up and enhances the performance of the system by minimizing or eliminating risks that may develop;

Production Control: This requires a follow up and checks on the production process to ensure it is in accordance with the planned output goals.

\subsection{The Role of Quantitative Analysis in Production Planning}

Although QA has been criticized to sometimes delay the speed required to take certain critical decisions and also confuse the entire process rather than improve it, the advantages of applying QA to a production planning process is quite enormous. Generally, QA has helped managers to;

1) Recognize risk and uncertainty in planning (by exposing the hidden risks and providing a more precise description of the cause and effect relationship in the business operations),

2) Decide on the proper deployment of resources for a project (by enabling managers identify key inputs, materials or machines that will yield the most income or ROI),

3) Minimize waiting time and servicing costs while increasing service level,

4) Minimize losses for organizations by assisting managers in choosing optimum strategy,

5) Decide on optimum resource allocation plan,

6) Decide when to buy and when to sell.

Finally, QA helps in facilitating the process of decision making as well as its accuracy by helping the manager select the best course of action in an uncertain system. Nevertheless, the success of the use of quantitative analysis in decision making is attributed to the fact that it is bereft of the subjectivity of human judgment or intuition.

\subsubsection{The Quantitative Analysis (QA) Models in Production Planning Decisions}

The QA models are data driven. Just like a manufacturing system, the QA process starts with data which is used or transformed into valuable insights for 
the decision maker. This means that the processing and transformation of raw data into meaningful insight is the core of QA. Memon [17] posits that one common characteristic of all QA models is that they involve numbers, symbols or mathematical formulae (or expressions) in their representation of reality. Today, there are several kinds of formal mathematical models and other types of models implemented in solving complex business problems. Different techniques are applicable to different decision making situations in organizations. It is this increasing number of ways that QA is being applied in business operations that has immensely contributed to it becoming a buzz word and a trending tool for decision making for production managers. Different levels of QA techniques and software packages used in solving complex production and management problems now exist.

These models and packages help managers; analysts as well as researchers make apt and accurate decisions. Some of the models of QA include; network analysis, linear programming, regression analysis, cost analysis (Break-Even Analysis), cost-benefit analysis, scenario analysis, risk analysis, decision tree analysis, inventory management, correlation analysis, simulation, sensitivity analysis, queuing, game theory, benchmarking, test for significance, etc. Nevertheless, the applicability and significance of QA in developing countries have been a source of argument; some studies argue that QA is applied in the production planning in developing countries like Nigeria [3] [18]. On another hand, some others argue that such decision-making techniques are irrelevant to the business operations of developing countries, and thus are not used there [19]. However, Nigerian organizations, especially the manufacturing firms (including small-scale industries) have few records of such level of applications of QA.

The application of quantitative techniques in planning and control activities of production management is therefore vast, especially as they enable managers to understand and predict organizations' production system. It is pertinent here, to note that these techniques only assist managers in understanding the production system and in taking decisions. These techniques on their own, do not help the production managers in decision making; they rather provide only a systematic approach to helping a decision-maker choose a course of action by investigating the problem, searching out objectives and alternatives, and comparing them with regards to their consequences using appropriate framework to bring expert judgment and intuition to bear on the problem [3]. However, for the purpose of this paper, focus will be on the most commonly used quantitative technique - linear programming.

\subsubsection{Limitations to the Use of Quantitative Analysis in the Decision-Making Process}

In the works of Bagshaw and Nissi [20], they believed that despite the acclaimed importance of applying QA in the production planning process, its applicability in decision making in production planning process comes to play only if:

1) The problem is first-hand; the manager has no prior experience to draw from. 
2) The problem is multifaceted; and the manager finds it difficult to develop a good solution without the aid of a methodology.

3) The problem is critical; wrong decision may lead to very grave outcomes and the manager needs to do an in-depth enquiry before making a decision.

4) The problem is constantly reoccurring and the manager needs to save time and effort.

\subsection{Linear Programming}

Linear programming is a general model used to decide the optimum mix and allocation of limited resources that will yield maximum profits or ensure minimum costs [21]. Earlier, Gupta and Hira [22] posit that programming in this case means planning, while linearity refers to a mathematical expression that shows relationship among a set of combined variables. The linear programming technique is a form of break-even analysis that helps managers know when they may be running at loss or making excess profit or even when to stop production. Linear programming involves the solution of linear equations and is useful when the manager needs to allocate scarce resources to competing projects or alternative production options. It applies to a single stage decision involved in determining optimal product mix, schedules, plant location, production capacity, assigning of personnel and machines to a task, distribution channel selection, investment portfolio selection, advertising channel selection [23].

In deciding which products to manufacture, what machine or technology to use, how many man hours to use and production duration; a problem is formed. Hillier and Lieberman [23] state that the introduction of linear programming in managerial decision making was rated as one of the most important advancement of the scientific management method of the mid-20th century owing to its exceptional impact right from the early 1950 [23] [24]. In support of this, the linear programming tool is rated as the most successful tool that has saved lots of money for businesses in various industrialized countries of the world [25] [26].

One of the classical applications of linear programming is in the production mix problem [27]. He further emphasized that the application of linear programming models are useful for; blending and mix determination problems, planning and scheduling problems and distribution cost problems and others such as plant location decisions and personnel allocation problems. However, before linear programming is applied in solving a problem, such problem must have objective functions, constraint function and have linearity in the relationship amongst all its variables linear property [26].

Gupta and Hira [22] argue that linear programming is a single objective constrained technique used for optimization problem in which the managers looks for how to combine several activities and resources in an optimal way to ensure overall efficiency is maximized. According to them, the linear programming model works towards solving a problem with either a minimization or maximization objective. Further, Gupta and Hira [22] argue that linear programming 
deals with the optimization of a combination of variables which are known as objective function in subjection to a set of linear equations known as constraints. While the objective is usually in form of profit, cost, production materials, production capacity or any other measure of success which is to be obtained in efficiently, the constraints are those limitations and restrictions imposed by available market demand, man hour, production processes, storage capacity, equipment, raw material.

Using linear programming to solve problems can either be done with a graph or an optimization technique called simplex method [23] [26]. For each of these methods, the objective is to arrive at the most optimal product mix, labour and plant utilization. However, whichever of these methods that the decision maker uses is dependent on the number of decision variables involved in the problem. This is because the graphical method can only be used when the decision variables are not more than two to represent the $\mathrm{x}$ and $\mathrm{y}$ axis on the graph. The decision variables being the main focus of the objective function are the units of products or cost element that require the utilization of the limited resources, the limited resources on the other hand, are the basis for the constraints that moderates any of the decision variables. Dwivedi [24] posits that in using linear programming to solve allocation problems, the problem needs to be specified in three parts which are, the objective function specification, constraint equation specification, and the non-negativity requirement. Again, Dwivedi [24] came up with two basic importance of applying linear programming in solving resource allocation problems in production planning which are;

1) it helps in measuring and multifaceted economic associations and thus offers an optimum solution to the problem of resource allocation,

2) it helps in bridging the gap between intangible economic theories and managerial decision-making. Wagner [25] emphasize that considerable evidences show the use of linear programming in solving resource allocation problems in production planning as it has significant impact on the economic objective of a firm, he stresses that it rank the highest in economic impact. It is argued that the linear programming method to resource allocation only shows the optimal plan or solution but does not say anything about its implementation [28].

The linear programming model is usually stated in an established function to aid proper analysis and ensure no important element is ignored. The function is presented in two parts;

\section{The Objective Function}

The objective function is a decision on what result is required, this may involve the maximization of desirable outcomes (profit, utility, revenue, employee outcomes, machine efficiency) or minimization of adverse outcomes (cost, time distance, weight, break down).

To obtain the objective function coefficients in a production mix problem, the decision maker needs to: 1) Estimate the contributory margin for each product, and; 
2) Estimate the absolute profit per unit of each product produced. The objective function is usually stated in this form:

a) Optimize $F=a_{1} x_{1}+a_{2} x_{2}+a_{3} x_{3}+\cdots+a_{n} x_{n}$

where, $a_{1}, a_{2}, a_{3}, \cdots, a_{n}$ are objective function coefficients and $x_{1}, x_{2}, x_{3}, \cdots, x_{n}$ are the decision variables.

\section{The constraint function}

The constraints are the limitations that guide the decisions or objective. It ensures that decision inputs do not exceed available resources. The constraints are however in two dimensions; functional (that is, input requirements and obligations within the confines of resources available) and quantity constraints. The constraint function is usually expressed as:

\section{Subject to:}

$$
\begin{aligned}
& b_{11} x_{1}+b_{12} x_{2}+b_{13} x_{3}+\cdots+b_{1 n} x_{n} \leq k_{1} \\
& b_{21} x_{1}+b_{22} x_{2}+b_{23} x_{3}+\cdots+b_{2 n} x_{n} \leq k_{2} \text { Functional Constraint } \\
& b_{31} x_{1}+b_{32} x_{2}+b_{33} x_{3}+\cdots+b_{3 n} x_{n} \leq k_{3} \\
& \vdots \\
& b_{m 1} x_{1}+b_{m 2} x_{2}+b_{m 3} x_{3}+\cdots+b_{m n} x_{n} \leq k_{m} \\
& x_{1}, x_{2}, x_{3}, \cdots, x_{n} \geq 0 \text { Quantity Constraint. } \\
& b_{11}, b_{12}, \cdots, b_{21}, b_{22}, \cdots, b_{31}, b_{32}, \cdots, b_{m 1}, b_{m 2}, \cdots, k_{1}, k_{2}, k_{3}, \cdots \text { are input coefficients } \\
& b_{i j}, i=1,2,3, \cdots, m ; j=1,2,3, \cdots, n \text { is the amount of resource } i \text { consumed by } 1 \\
& \text { unit of activity } j .
\end{aligned}
$$

In the general solution of LP problems, the maximization problems usually have constraints of less than or equal to $(\leq)$ values, while the minimization problems have constraints of greater than or equal to $(\geq)$ values. Using linear programming to solve problem can either be done with a graph or an optimization technique called simplex method [23] [26]. For each of these methods, the objective is to arrive at the most optimal product mix, labour and plant utilization. However whichever of these methods that the decision maker uses is dependent on the number of decision variables involved in the problem as graphical method can only be used when the decision variables are not more than two which will represent the $\mathrm{x}$ and $\mathrm{y}$ axis on the graph. The decision variables being the main focus of the objective function are the units of products, man hour or cost element that requires the utilization of the limited resources, the limited resources on the other hand, are the basis for the constraints that moderates any of the decision variables.

The general model of linear programming for both maximization and minimization objectives is as shown below:

b) Maximize $P=a_{1} x_{1}+a_{2} x_{2}+a_{3} x_{3}+\cdots+a_{n} x_{n}$

\section{Subject to:}

$$
\begin{aligned}
& b_{11} x_{1}+b_{12} x_{2}+b_{13} x_{3}+\cdots+b_{1 n} x_{n} \leq k_{1} \\
& b_{21} x_{1}+b_{22} x_{2}+b_{23} x_{3}+\cdots+b_{2 n} x_{n} \leq k_{2} \\
& b_{31} x_{1}+b_{32} x_{3}+b_{33} x_{3}+\cdots+b_{3 n} x_{n} \leq k_{3}
\end{aligned}
$$


$b_{m 1} x_{1}+b_{m 2} x_{2}+b_{m 3} x_{3}+\cdots+b_{m n} x_{n} \leq k_{m}$

$x_{1}, x_{2}, x_{3}, \cdots, x_{n} \geq 0$

c) Minimize $C=a_{1} x_{1}+a_{2} x_{2}+a_{3} x_{3}+\cdots+a_{n} x_{n}$

Subject to:

$$
\begin{aligned}
& b_{11} x_{1}+b_{12} x_{2}+b_{13} x_{3}+\cdots+b_{1 n} x_{n} \geq k_{1} \\
& b_{21} x_{1}+b_{22} x_{2}+b_{23} x_{3}+\cdots+b_{2 n} x_{n} \geq k_{2} \\
& b_{31} x_{1}+b_{32} x_{3}+b_{33} x_{3}+\cdots+b_{3 n} x_{n} \geq k_{3} \\
& \vdots \\
& b_{m 1} x_{1}+b_{m 2} x_{2}+b_{m 3} x_{3}+\cdots+b_{m n} x_{n} \geq k_{m} \\
& x_{1}, x_{2}, x_{3}, \cdots, x_{n} \geq 0
\end{aligned}
$$

The trend in the applicability of linear programming in production planning has gradually cascaded to developing countries like Nigeria. This is shown in studies carried out by several scholars such as: Kareem and Aderoba [29] who, from the data collected from a cocoa processing industry in Ondo State, Nigeria, established the effectiveness of adopting the linear programming model in the maintenance and manpower planning. Their study showed that only four maintenance crew out of the 19 employees are needed in that section to effectively carry out maintenance jobs in the industry, thus minimizing manpower related cost for the cocoa production firm.

In another study, Adeyemo and Otiero [30] who, demonstrating the extension of the linear programming model to the Physical and Environmental Sciences, was able to establish the efficacy of applying linear programming (LP) in maximizing total income. Also Ezema and Amakon [18] were able to optimize profit for Golden Plastic Industry Limited, Enugu, Nigeria by applying the linear programming model to determine the most profitable product mix from the eight PVC pipes produced by Golden Plastics Industry which were differentiated by their sizes, thickness and length. Through the application of linear programming, optimal quantities of the various PVC pipes that would maximize profit were established. These research evidences show the practical proofs of the workability and efficacy of the linear programming model which goes a long way to reiterate the advantage of going beyond mere intuitive (qualitative) decision making to the application of evidence-based tools (quantitative techniques) in decision making for manufacturing firms.

\section{Conclusions}

To an extent, the adoption of the use of quantitative analysis in decision making in organizations is becoming a contemporary management issue. This assessment revealed that the "best-fit" application of quantitative analysis models and tools can untangle the complexities of production and planning decision making process in other to achieve the organizational goal. Although literature has shown there is obviously no consensus or integrated model that is capable of solving all managerial problem, different models such as the linear programming 
model have however been developed to cater for different problems as they arise. The workability of quantitative analysis is actually in its appropriate application. This implies that before a particular technique is applied, the ultimate objective, which is the solution to the problem, must be understood.

Furthermore this review revealed that the use of linear programming is now a contemporary quantitative analytical tool for enhancing the decision making process in manufacturing firms. Adhering to the QA methodology will profoundly change the way managers think about their problems; particularly on how they measure the problem, gain hidden information, relate them to other problems, communicate with other people about them, and gather information for solving them. There is also the ever increasing demand for managers to possess analytical and numerate ability and skills to enable them analyze and interpret problems from both within and outside the organizations effectively. In the competitive and dynamic world of manufacturing, the organizations that will likely succeed, and indeed survive are those that appropriately apply management tools such as quantitative techniques.

This paper has attempted to give a concise assessment of the role of a quantitative analytical tool for decision making and its ever-increasing importance due to the complexity in decision making resulting from the ever-changing business environment. In addition, the paper was able to establish the trend in the applicability of one of the most commonly used QA techniques-linear programming model in the manufacturing sector in solving production planning decisions. Thus, quantitative analysis is said to play significant roles in providing reliable evidence based decision for manufacturing firms today.

\section{Recommendations}

Having reviewed the manufacturing firm's production planning decisions with the application of QA through the use of linear programming models, this paper recommends that:

1) The importance of QA and the complexity in the process of problem solving due to global changes in the business world makes it necessary for managers of business organizations to be analytical and numerate regardless of their background.

2) With the advancement in technology, the evolution of more powerful QA computing techniques is emerging and production managers are to explore new methods to avail themselves of the opportunities in production planning decisions.

3) The knowledge of the appropriate application of QA by business managers must not be overlooked if an organization intends to be proactive, dynamic, resilient and efficient in the face of environmental changes.

4) It is required that manufacturing firms carry out periodic training on quantitative skills for their employees to expose and equip them with the knowledge and awareness of QA and its importance for organizational development. 


\section{Conflicts of Interest}

The author declares no conflicts of interest regarding the publication of this paper.

\section{References}

[1] NBS (2013) National Survey Report. FCT, Abuja.

[2] Cooper, L.G. and Nakanishi, M. (2010) Market-Share Analysis: Evaluating Competitive Marketing Effectiveness. Kluwer, Boston.

[3] Anene, E.C. and Oyelere, B.A. (2014) An Evaluation of the Applications of Quantitative Techniques (QTs) to Production Planning and Control in Manufacturing Industries. European Journal of Business and Management, 6, 23-30.

[4] Verma, G. and Sharma, K. (2017) The Role of Quantitative Techniques in Business and Management. Journal of Humanities Insights, 1, 24-26. https://doi.org/10.22034/JHI.2017.59559

[5] Mishra, P.N. and Jaisankar, S. (2007) Quantitative Techniques for Management. School of Distance Education, Bharathiar University, New Delhi.

[6] Robbins, S.P. and De Cenzo, D.A. (2001) Fundamentals of Management e-Business (Updated Ed.). Prentice Hall, London.

[7] Merton, R.C. and Samuelson, P.A. (1974) Fallacy of the Log-Normal Approximation to Optimal Portfolio Decision-Making over Many Periods. Journal of Financial Economics, 1, 67-94. https://doi.org/10.1016/0304-405X(74)90009-9

[8] Bendian, A.G. and William, G.F. (1983) Management. The Dryden Press, Chicago.

[9] Jain, L.C. and Lim, C.P. (2010) Handbook on Decision Making. Vol. 4, Springer-Verlag, Berlin Heidelberg, 163-179. https://doi.org/10.1007/978-3-642-13639-9

[10] Luthans, F. and Kreitner, R. (1985) Organisational Behaviour Modification and Beyond: An Operant and Social Learning Approach. McGraw-Hill, New York.

[11] Wazis, R.H., Imam, Y. and Kashim, M. (2016) Decision Making as a Tool for Organisational Development (A Case Study of Borno State High Court of Justice Maiduguri). European Journal of Business and Management, 8, 85-93.

[12] Filippo, E.B. and Mussinger, G.M. (1982) Management. Allyn and Bacon, Incorporated, New York.

[13] Harris, R. (1998) Introduction to Decision Making. Virtual Salt. http://www.virtualsalt.com/crebook5.htm

[14] Daft, R.L. (1998) Organization Theory and Design. 6th Edition, South Western College Publishing, Cincinnati.

[15] Bagshaw, K.B. (2017) Process and Product Design: Production Efficiency of Manufacturing Firms in Rivers State, Nigeria. Engineering Management Research, 6, 49-55. https://doi.org/10.5539/emr.v6n1p49

[16] MacCarthy, B. (2006) Organizational Systems and Human Issues in Production Planning, Scheduling and Control. Springer, New York.

[17] Memon, A.Z. (2005) Quantitative Methods and Industrial Challenges. Journal of statistics, 12, 1-10.

[18] Ezema, B. and Amakon, U. (2012) Optimizing Profit with the Linear Programming Model: A Focus on Golden Plastic Industry Limited, Enugu, Nigeria. Interdisciplinary Journal of Research in Business, 2, 37-49.

[19] Argozie, C.J. (2005) A Study of the Application of Operations Research Methodol- 
ogy Incorporate Decision-Making in Selected Manufacturing Firms in Nigeria. An Unpublished PhD Thesis, Department of Management and Accounting, Faculty of Administration, Obafemi Awolowo University, Ile-Ife.

[20] Bagshaw, K.B. and Nissi, K.L. (2019) Trend in Viewing Quantitative Analysis as a Primary Function Involving Decision Making in Organizations. American Journal of Industrial and Business Management, 9, 1492-1505.

https://doi.org/10.4236/ajibm.2019.96099

[21] Bronson, R.M. (1997) Schaums Outline Series. 2nd Edition, McGraw-Hill, New York.

[22] Gupta, P.K. and Hira, D.S. (2009) Operations Research: An Introduction. S. Chand and Hall, New Delhi.

[23] Hillier, F.S. and Lieberman, G.J. (2004) Introduction to Operations Research. McGraw-Hill, New York.

[24] Dwivedi, D. (2008) Managerial Economics. VIKAS Publishing House PVT Limited, New Delhi.

[25] Wagner, H. (2007) Principles of Operations Research with Application to Managerial Decision. Prentice Hall Press Ltd., Upper Saddle River.

[26] Lucey, T. (2007) Quantitative Techniques. Letts Educational Addice Place, London.

[27] Taha, H.A. (2006) Operations Research: An Introduction. Prentice-Hall, New Delhi.

[28] Koutsoyiannis, A. (1987) Modern Microeconomics. English Language Book Society, Macmillan.

[29] Kareem, B. and Aderoba, A. (2008) Linear Programming Based Effective Maintenance and Manpower Planning Strategy. International Journal of the Computer, the Internet and Management, 16, 26-34.

[30] Adeyemo, J. and Otiero, F. (2009) Optimizing Planting Areas Using Differential Evolution and Linear Programming. International Journal of Physical Sciences, 4, 212-223. 